Article

\title{
Generations Comparison: Father Role Representations in the 1980s and the New Millennium
}

\author{
Maria Letizia Bosoni * and Sara Mazzucchelli (iD \\ Department of Sociology, Catholic University of Milan, 1, 20123 Milano MI, Italy; sara.mazzucchelli@unicatt.it \\ * Correspondence: marialetizia.bosoni@unicatt.it
}

Received: 22 January 2019; Accepted: 3 April 2019; Published: 9 April 2019

check for

updates

\begin{abstract}
In the light of relevant and current debate on the changing role of fathers, this contribution is aimed at analysing the international literature on fatherhood, comparing two distinct periods of time, from the social, cultural and demographic point of view: the years 1980-1999 and the new millennium. This will contribute to identifying features of the fatherhood transformation in these two contexts, which in fact refer to two generations of fathers. The research questions to be answered are: Which aspects characterize the process of fatherhood transformation, in an intergenerational perspective? How are paternal childcare practices represented in different historical and social periods? An analysis of the academic publications on fathers in Scopus and Google Scholar will be conducted, in the two temporal periods indicated, using T-Lab software, in order to map fathers' role representations.
\end{abstract}

Keywords: father; family; generations; transformation

\section{Introduction}

Reflection on fatherhood and its transformation is now a global phenomenon, with many studies highlighting that men and fathers are more visible and present in the care of their children, compared to the past. However, how it clearly indicates a radical transformation of the paternal role is the subject of great debate in many countries (Miller and Dermott 2015; Craig and Mullan 2010).

Research from different countries (Magaraggia 2013; Bosoni 2014a, 2014b; Bosoni et al. 2016; Ruspini and Tanturri 2017) reports the growing importance of the father figure in the family context and a greater desire and willingness of the father to be present in childcare, with more involvement in practical care activities (O'Brien and Wall 2015; Miller 2011; Gregory and Milner 2011; Lamb 1999). Thus the complex issue of reconciling family and work, long considered purely feminine, is increasingly seen as a paternal responsibility. In this sense, policies (in particular leave schemes) have certainly given a significant impetus: the paternal role is increasingly recognized in the contemporary debate.

Despite the greater involvement of fathers in the care, they still play a secondary role in the family and are mainly dedicated to ludic activities rather than to physiological care, especially in early childhood (Bosoni 2014b; Tanturri and Mencarini 2009; O'Brien 2009). Therefore, although the studies highlight a greater emotional connection between fathers and sons and the rise of a new model of fatherhood and masculinity (the terms "new fathers" and "loving fathers", in opposition to traditional terms, are particularly widespread), we cannot conclude that there has been a radical overcoming of the breadwinner model (Gillies 2009; Perra and Ruspini 2013). This applies to many countries, including Italy; traditional models coexist with new paternal practices and styles and it is not possible to identify a single prevailing model.

From 2000, studies on fatherhood have increased, reporting a process of transformation and renewal of fathering practices. In particular, qualitative studies have revealed the relevance of intergenerational transmission: contemporary fathers define themselves in relation to the previous 
generation (i.e., one's own father) and often in terms of differences ("I am different from my father") from the traditional model, while the traditional model still serves as a form of internalized reference that is no longer seen to be applicable in today's society. However, the relationship between one generation and the next is complex, as the old interiorised model is in tension with new life style (Bosoni and Baker 2015).

In this contribution we intend to discuss in particular this generational difference, by analysing the literature about fathers in two different periods, corresponding to two distinct generations: the years 1980-1999 and 2000-2017.

It is important to point out how we intend the meaning of generation, inspired by relational sociology (Donati 2011): generation is conceived as the set of people who share a relationship, linking their place in the family-parental sphere (i.e., child, parent, grandfather, etc.) with the position they have in the whole society according to their social age (i.e., according to age groups: young people, adults, elders, etc.) (Terenzi et al. 2016). Considering generation as a relationship between the intra-family dimension and social collocation allows us to think about generations in a new way: as a phenomenon that characterizes individuals, families and society in different ways but linked to one another. A generation cannot be made by a single family, just as it cannot be done by society alone. A generation instead consists of the subjects who are in a context of relationships in which the same age-not merely biological but according to a historical and social time-connects the way of being in the family and in the society (Donati and Colozzi 1997).

In doing our analysis we take in mind this definition of generation. In the following paragraphs we will firstly review the studies on fathers, highlighting the main features and themes and then we will analyse the international literature by using T-lab software, comparing two distinct periods from the social, cultural and demographic point of view-1980-1999 and 2000-2017-in order to identify the distinctive features of fathering/fatherhood in these two contexts, which represent two generations of different fathers ${ }^{1}$. The specific research questions we will try to answer are these:

- Which aspects characterize the process of transformation of fatherhood, in an intergenerational perspective?

- How are paternal childcare practices represented in different historical and social periods?

\section{Research on Fatherhood: Between Change and Continuity}

Studies on fatherhood agree in highlighting in the contemporary context, albeit with different emphasis, an image of loving and tender father, in opposition to the traditional ideal (severe and not accustomed to the expression of emotions). In particular, the expectations on fatherhood highlight a desire to be actively present: the fathers even before birth identify themselves as an involved and caring parent and define themselves as a "good father" (Miller 2011). At the same time, however, some authors have begun to reflect critically on this fatherhood transformation process, questioning what is really "new" in the parenting style of today's fathers. Male identity seems to be still strongly associated with the idea of breadwinner, the man who takes care of the economic support of the family through extra-domestic work, so that alongside the desire to be a good father and a father involved in childcare there is also a desire to be a good economic provider. According to Dermott (2008), the distinction of the two elements (breadwinner and involved father) as opposites is produced by our instinct to dichotomize reality and use opposite categories, although the two elements can also coexist. Dermott, in fact, described paternity through the concept of "intimate fatherhood", where the idea of intimacy

1 The choice of these periods originated above all by the fact that according to Scopus database publications on fatherhood increased from 2000, particularly in the Social Sciences. Therefore, the selected publications in these two time periods represent on the one hand research on men involved in the transition to fatherhood in specific life-span (although with age differences), on the other hand they report the representation of eminent scholars in two distinct time and social periods. 
refers to a personal and particular relationship, characterized by presence; closeness; expression of emotions; reciprocity; and dyadic, one-to-one relationship.

The relationship between fatherhood and motherhood is also central in the father's identity formation (Bosoni 2014b): male identity is formed starting from an imaginary set of ideas and representations deriving both from an intergenerational legacy and from current relationships, in particular the relationship with the partner. What seems to emerge more and more clearly-though not always consciously-is a relational dynamic where fatherhood can be understood in relation to motherhood. Moreover, this tendency to bring parenthood closer to motherhood (sometimes called "homogenization" or "de-differentiation" of parental roles) does not actually produce a flattening of differences, which are enhanced (Doucet 2006).

Studies have also revealed the intergenerational transmission of fathering/fatherhood (Brannen and Nilsen 2006; Bosoni 2014b): the relationship with the previous generation is fundamental as it constitutes the internalized reference model, with referent to both meanings and practices of being a father, which need however be adapted to the contemporary social and family context.

Furthermore, the debate on the fathering transformation is strongly connected with the cultural dimension, namely "the rules, values, beliefs and symbolic representations of paternity" (LaRossa et al. 2000, p. 375). These aspects define the expectations connected to being a father, which can assume various connotations in different social-historical contexts, for example, in Western industrialized societies we can identify at least three socially and normatively recognized aspects: "the father as an economic provider for the family", "the father as a male model of reference for sons and daughters" and "the father as a playmate" (LaRossa 2007, p. 89).

The symbolic-cultural dimension of fatherhood also indicates the importance and relevance of the paternal figure: how fathers are considered as competent caregivers, what is transmitted between generations about being a father (specific tasks and activities, work vs. care) and expectations about what fathers do towards the children. Moreover, the symbolic dimension of fatherhood reveals a great deal about the culture of fatherhood: the Father's Day, the male and paternal representation in films or books (LaRossa 2007). This contributes to defining the social expectations of fatherhood-what a father is expected to do or not.

Under great discussion is also how much the cultural dimension of fatherhood has changed over time. LaRossa and colleagues (LaRossa and Reitzes 1993; LaRossa et al. 2000) analysed the media representations of Father's Day and Mother's Day in America between 1940 and 1999, highlighting a drop of the patriarchal and absent father since the 1950s in favour of a father more involved in the care of children and less authoritarian that they found with greater force in the 1990s. This study highlights a change in the culture of fatherhood, although authors conclude that it is not possible to describe the extent of this transformation as it is characterized by a non-linear process. What is clear is that the cultural dimension of parenthood changes over the centuries but not in a linear or simple way. As a consequence, paternal practices in terms of activities and involvement with their children vary widely in different social, economic and political contexts (Coleman and Ganong 2003). This is also confirmed by more recent studies (Marsiglio et al. 2000) that highlight the presence of different fathers' styles, defined as "fatherhood diversity" to indicate the presence and coexistence of traditional and new models, not necessarily in conflict. The renewal process of fatherhood (well expressed by the term "new fathers") is actually linked with a tension between tradition and modernity, in which the new coexists with the old, as paternity is expressed in different ways and there is not a single model of reference. Several research studies in the European context have agreed on this variability (Zajczyk and Ruspini 2008; Naldini and Torrioni 2015; Crespi and Ruspini 2016).

Thus, the cultural dimension of fatherhood-including symbolic and normative aspects—and fathering practices-aspects related to the care of a child-are two different but strongly linked dimensions of fathers' experience. The cultural dimension is certainly not easy to detect, as the operationalization of values and orientations behind the paternal role is a very debated question; even the definition of the concept of value is so complex that some authors speak of a terminological 
jungle (Halman 1995) or black box (Hechter 1993), pointing out that in social research we can only grasp beliefs, attitudes and opinions, which are assumed to refer to values guiding human action (Cipriani 2012).

For this reason, many studies have focused on paternal practices (fathering), highlighting in particular involvement with young children (Yeung et al. 2001; Brotherson et al. 2005) and the desire to be good fathers (Morman and Kory 2006); less explored is the process by which men come to define themselves as fathers (fatherhood). Regarding this last aspect, the studies also agree in highlighting an intergenerational dimension of fatherhood, namely the need to relate with one's father to define the actual experience. This suggests that the perception of what a father should be in the family context always occurs in relation - and by difference-with the previous generation, which represents the internalized reference model although it is not completely pertinent to the contemporary context (Brannen and Nilsen 2006). It should be noted, however, that despite the emphasis on the greater recent involvement of fathers in family care, data still show the presence of a gap between tasks and responsibilities in the couple, confirming that the father often assumes a role of secondary caregiver, especially when children are young (Finn and Henwood 2009). Although research studies have mainly taken into consideration the relationship between fathers and young children, recently some research has highlighted the relational dynamics underlying the bond between father and son in adolescence (McKinney and Renk 2008).

Moreover, fatherhood can be considered as a transition influenced by different personal, social and family factors (Palkovitz and Palm 2009): it is a process of skills learning (fathering) ${ }^{2}$ that contributes over time to define their own experience (Coleman and Ganong 2003; Dermott 2008; Featherstone 2009; Hobson 2002). Recently, the debate on fatherhood has highlighted the important link between fatherhood (often emphasizing the "right" of fathers to care for their children) and work, thus contributing to redefine the complex issue of family-work reconciliation as a problem that is not only female (Bosoni 2014a; Mazzucchelli 2011). The role of policies (leaves) in particular has been highlighted in supporting fathers to share parental responsibilities (Rossi et al. 2009).

Scholars have more recently focused on childcare tasks and their division in the family as well as work and family balance, with a gender perspective (Tanturri and Mencarini 2009; Magaraggia 2013; Ruspini and Tanturri 2017). Furthermore, it is becoming increasingly clear that choices regarding the division of tasks between parents have undergone a decision-making process by the couple, rather than the individual, in which paternal and maternal competencies are not blurred but valued as different (Rossi and Mazzucchelli 2011).

From what has been said so far, it is clear that the concept of fatherhood is multifaceted and complex; in the same society and historical epoch, in fact, different interpretations of the paternal role can coexist, even in contrast with each other (e.g., "absent father" and "new father"). Therefore, rather than looking for the prevailing/appropriate model, it is interesting to document and explore diversity, which as we said is also and above all generational. For this reason, in this contribution we analyse this last aspect by giving voice to the literature of two different epochs.

\section{Analysis of the Studies in Two Historical-Temporal Contexts}

In this paper we review the international literature on fatherhood, distinguishing and comparing two distinct time periods, which represent two generations of different fathers: the years 1980-1999 and the new millennium (2000-2017).

2 Several studies confirm that fatherhood is perceived as something that must be learned, in opposition to the motherhood that is considered by fathers as a natural and biological (Miller 2011; Bosoni 2014b). 
The specific research questions to be answered are:

- Which aspects characterize the process of transformation of fatherhood, in an intergenerational perspective?

- $\quad$ How are paternal childcare practices represented in different historical and social periods?

We carried out an analysis of the most relevant academic publications in Google Scholar concerning the paternal figure in the two time periods indicated, through T-Lab software, with particular attention to the theme of intergenerational transmission of parenthood and parenting, in order to identify the distinctive traits of fatherhood in these two historical-temporal contexts.

These distinctive features are indicated by key words that the TLab software can highlight and analyse, showing the relationships graphically. This method allows us not only to deeply analyse selected literature in a specific period, identifying key concepts but also providing a useful comparison of different studies on fathers.

The thematic analysis allowed us to map the representations of paternity, highlighting the intergenerational aspects and the declinations associated with them.

\subsection{Methodology}

First we identified the main sociological and psychological publications in Google Scholar in the two time periods (1980-1999, 2000-2017), inserting keywords to guide the research: father's involvement, fatherhood, fathering, intergenerational transmission of fatherhood, fathers and adolescent sons. Then we selected the 10 most relevant papers for each historical period according to the relevance order given by Google Scholar, number of citations and the relevance of journals in which it was published (i.e., Journal of Marriage and the Family, Family Relations, Fathering ... ).

The complete texts of the selected articles were analysed. As a method of analysis we used T-LAB, which consists of a set of linguistic and statistical tools for content analysis and text mining allowing a graphic and synthetic representation of relationships between words and concepts ${ }^{3}$.

The wealth of the designated corpus allowed us to carry out analyses of different types and complexities: word associations, radial diagrams and sequence analysis. We will discuss them in order.

From a preliminary analysis of the keywords in the 1980-1999 literature (Table 1, columns 1 and 2) we can see that the words with the highest occurrence values are "father" (1735) and "child" (1181). "Mother" (655), "parent" (605), "family" (601), "relationship" (471) and "adolescent" (421) follow at a distance but with significant values.

In the most recent literature (2000-2017) (Table 1, columns 3 and 4) we can see how the words with the highest occurrence values are again "father" (1169) and "child" (652). "Man" (373), "family" (318), "fatherhood" (282), "involvement" (279) and "mother" (277) follow at a distance but with significant values.

In comparing the two periods, some interesting elements emerge: in the years 1980-1999 the literature deals with the subject of paternity by focusing on the substantial difference present in the parental couple, that is, the difference with the maternal figure; there is also a large focus on the transition to adolescence; in today's literature the focus is on the theme of masculinity in relation to fatherhood (we speak of father but also of fatherhood); paternal involvement assumes a decisive role ("involvement", "involve"), as does that of care ("care") and of the relationship with the world of work. The focus is not on the difference but on the relationship, with the mother figure and between the different areas of life.

3 There are several valuable elements of this program: its interface is particularly user-friendly and allows an application to very different fields and objects as well as automatic lemmatization available in several languages (Italian, English, French, German, Spanish and Portuguese). T-LAB also uses automatic and semi-automatic processes that allow you to quickly highlight significant patterns of words, themes and variables; finally all software processes are transparent and can be easily customized using a wide and flexible range of analysis tools (for deep explanation visit https://tlab.it/en/presentation.php). 
Table 1. Keywords with relative occurrence values: comparative analysis between 1980-1999 and 2000-2017.

\begin{tabular}{cccc}
\hline & $\mathbf{1 9 8 0 - 1 9 9 9}$ & & $\mathbf{2 0 0 0 - 2 0 1 7}$ \\
\hline Keywords & Occurrence Values & Keywords & Occurrence Values \\
\hline father & 1735 & father & 1169 \\
child & 1181 & child & 652 \\
mother & 655 & man & 373 \\
parent & 605 & family & 318 \\
family & 601 & fatherhood & 282 \\
relationship & 471 & involvement & 279 \\
adolescent & 421 & mother & 277 \\
study & 392 & time & 245 \\
time & 362 & study & 233 \\
difference & 303 & involve & 223 \\
parenting & 299 & work & 195 \\
sex & 292 & care & 193 \\
interaction & 273 & relationship & 179 \\
man & 267 & experience & 177 \\
involvement & 261 & role & 169 \\
behaviour & 260 & parenting & 168 \\
measure & 247 & change & 162 \\
work & 246 & activity & 153 \\
daughter & 241 & research & 147 \\
role & 218 & parent & 146 \\
need & 206 & good & 137 \\
analysis & 200 & son & 137 \\
age & 198 & social & 133 \\
research & 197 & transition & 133 \\
girl & 195 & important & 126 \\
\hline
\end{tabular}

The comparison of key words in the two periods considered which represent two distinct generations highlights continuity rather than discontinuity in fathers representation: father-mother-child relation is central in both periods, then a focus on masculinity emerges along with the idea of being a good father.

We will now analyse in more detail the specificities of the studies on paternity in the two temporal periods, through ad hoc elaborations.

\subsection{Studies on Fatherhood in the Period 1980-1999}

\subsubsection{Radial Diagrams}

In radial diagrams the selected lemma is placed at the centre, with the others distributed around it, each at a distance proportional to its degree of association. The relations brought to light are therefore all significant according to a one-to-one relationship between the central lemma and each of the others.

The lemma "father" (Figure 1) - as a central keyword in word associations-is associated with different subjects in relation to which the paternal function is explicit (child, in the differentiation of son and daughter but also mother) and better defined as a role that is played in the family and connected to practical parenting practices ("support", "suggest", "involve", "involvement", "spend time"). Fatherhood is linked to the generative but also the work dimension. The themes of change and masculinity ("man") are also central. 


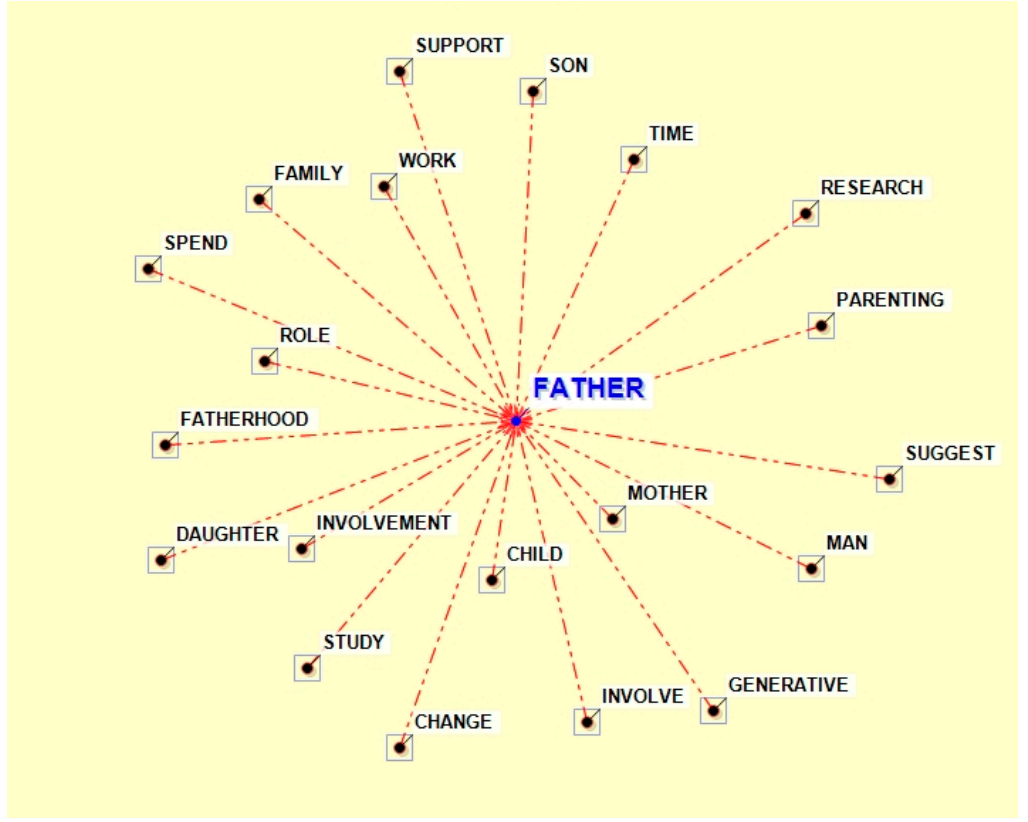

Figure 1. Radial diagram with "father".

The lemma "child" (Figure 2)—in the second place as a keyword in word associations—seems to mirror what has already been highlighted with the lemma "father". It is in fact associated with mother, father, parent and concrete actions in which the dimension of parental care is clarified ("care", "parenting"): "spend time", "involvement", "support". The relational ("relationship", "interaction") and value dimension ("belief") and attention to the needs of the child are central.

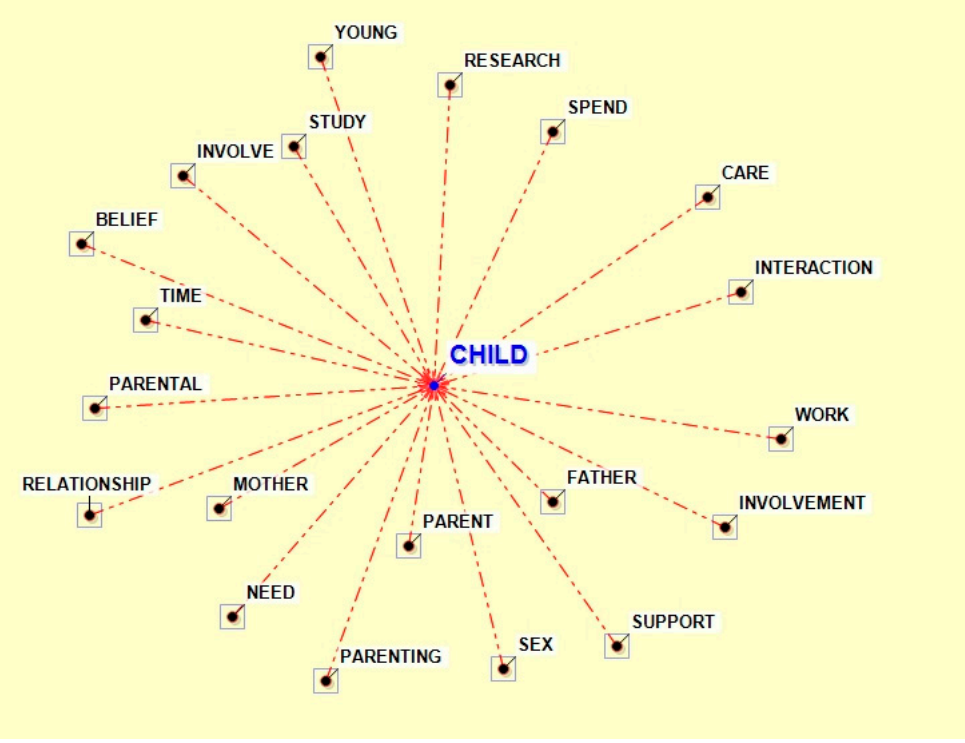

Figure 2. Radial diagram with "child".

The lemma "mother" (Figure 3) —in third place as a keyword in word associations-is also in line with the results highlighted by the lemma "father", albeit with some specificities. The theme of the difference of gender ("boy", "girl", "daughter") and of age ("old", "young", "age") of the children ("child") emerges as decisive; the maternal figure is also defined by difference with the paternal figure ("father") within the family context in which the parental dimension is strongly felt ("parent", "parenting") and has peculiar characteristics. In addition to the theme of involvement and spending 
time the relationship that is connoted as supportive is emphasized. The focus on the adolescent condition is also interesting.

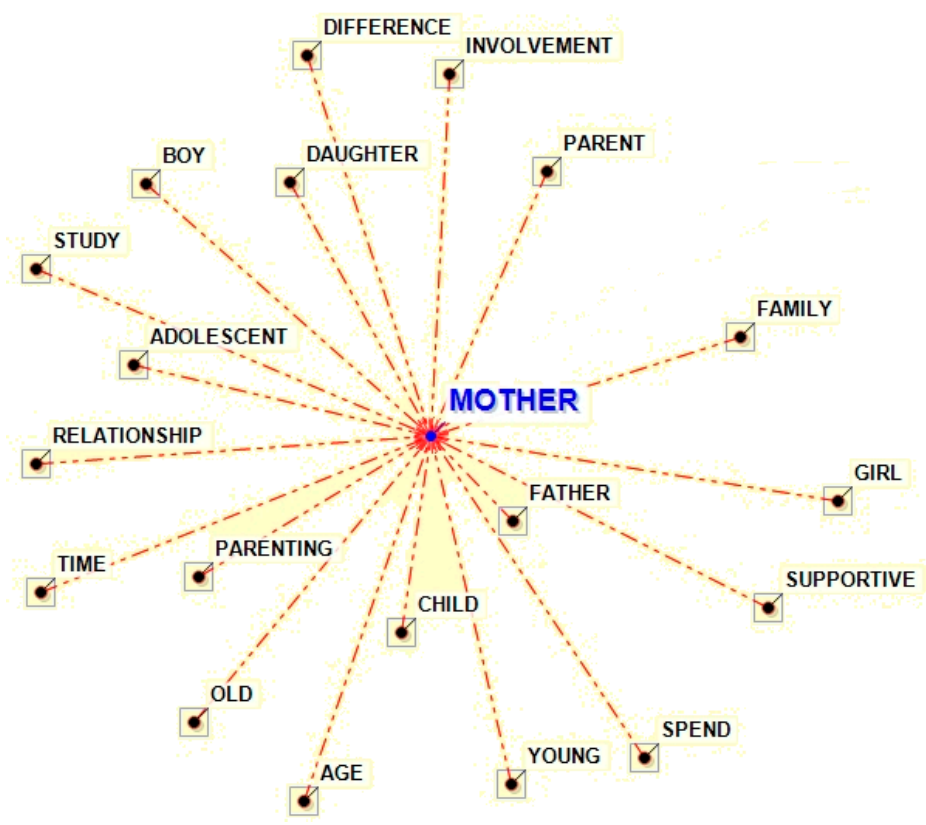

Figure 3. Radial diagram with "mother".

The lemma "parent" (Figure 4)-in fourth place as a keyword in word associations-takes up some elements already mentioned in the other words and emphasizes other new aspects: parenting has to do with specific expectations ("expect") and values ("beliefs") that translate into parenting practices and behaviours in which the relationship ("interaction") is centred on a strong disciplinary aspect ("disciplines"). It is interesting, again, to see the emphasis on difference, either in the paternal or maternal code ("mother", "father") or in relation to the children. Rather than the gender difference ("sex", "boy"), the age difference is more emphasized, focusing on the change in the parental role in the growth of children ("developmental") and especially in the adolescent phase.

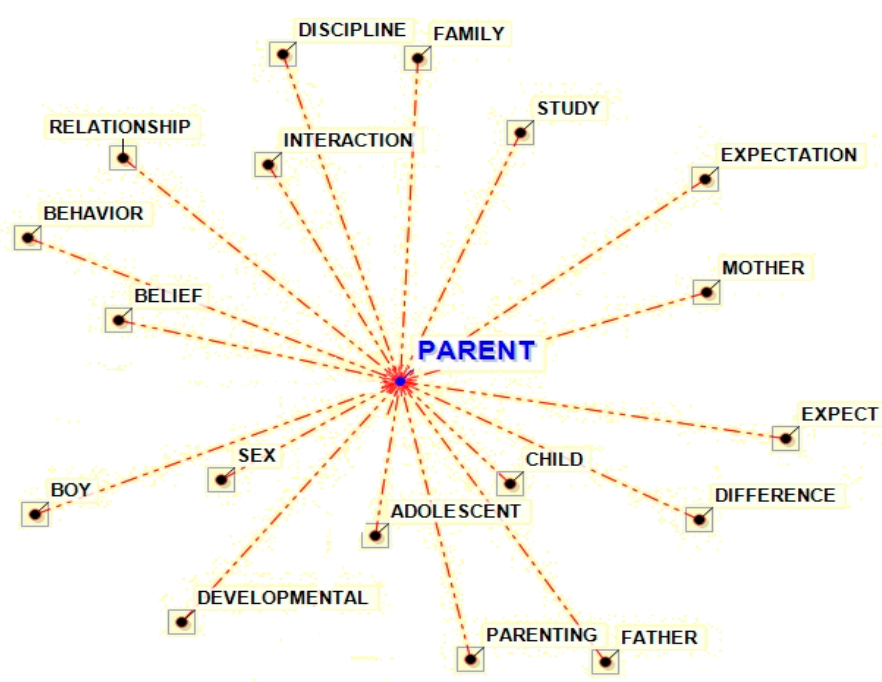

Figure 4. Radial diagram with Parent. 
Finally, the lemma "adolescent" (Figure 5) is interesting because it shows us the focus of the studies conducted in the considered period (1980-1999); it is a survey (study, rating, exploration, rate, sample) in which some specific themes related to identity are investigated: "discrepancy", "achievement", "expectation", "belief", "task".

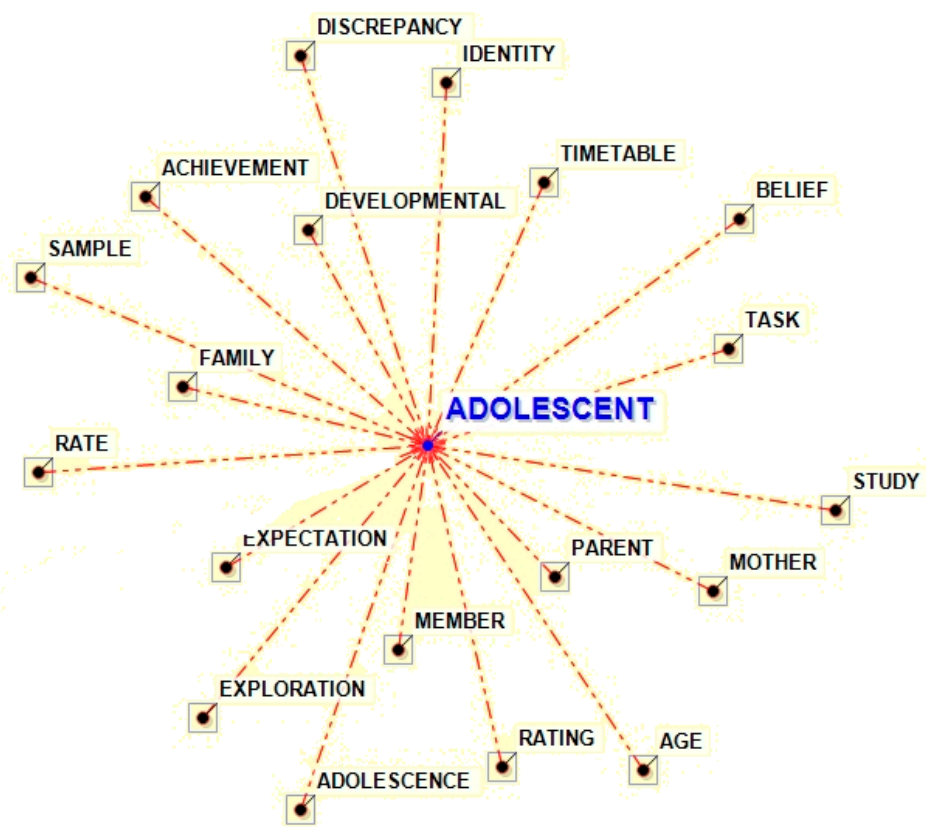

Figure 5. Radial diagram with "adolescent".

What is fundamental is the reference to the family and the relationship with the parental figures (parent), in particular the mother.

\subsubsection{Sequence Analysis}

T-LAB allows the researcher to calculate for every lexical unit the predecessors and successors: in the produced graphs, lexical units less distant from the selected one are those that are more likely to precede it (predecessors) or follow it (successors) ${ }^{4}$.

Focusing on the analysis of keyword sequences, Figure 6 shows all the predecessors and all the successors of the lexical unit "father". The strongest predecessor is "mother", followed by "generative", "responsible" and "child"; predecessors present but less relevant than these are "time", "interest", "influence", "role", “definition" and "work".

4 The T-LAB software allows to perform a Markov analysis of three types of sequences and to export the related outputs for a Network Analysis.The types of sequences that can be analyzed are the following:

(A) Keyword Sequences, the elements of which are lexical units (words or lemmas) present in the corpus or in a subset of it. In this case the maximum number of 'nodes' ('types' of lexical units) is 3000;

(B) Sequences of Themes, whose elements are units of context (ie elementary contexts) classified by a T-LAB tool for thematic analysis (Thematic Analysis of Elementary Contexts, Classification Based on Dictionaries or Modeling of Emerging Themes). In this case, since the sequence of elementary contexts characterizes the whole 'chain' (predecessors and successors) of the corpus, T-LAB realizes a specific form of analysis of the speech, whose nodes can vary from a minimum 5 to a maximum of 50;

(C) Sequences stored in a Sequence.dat file prepared by the user. In this case the maximum number of records is 50,000 and the number of 'types' (i.e., nodes) must not exceed 3000.

Starting from a matrix in which all the predecessors and all the successors of each item are registered (lexical unit or theme), T-LAB calculates the transition probabilities (Markov chains) between the various units of analysis thus identifying predecessors and successors. 


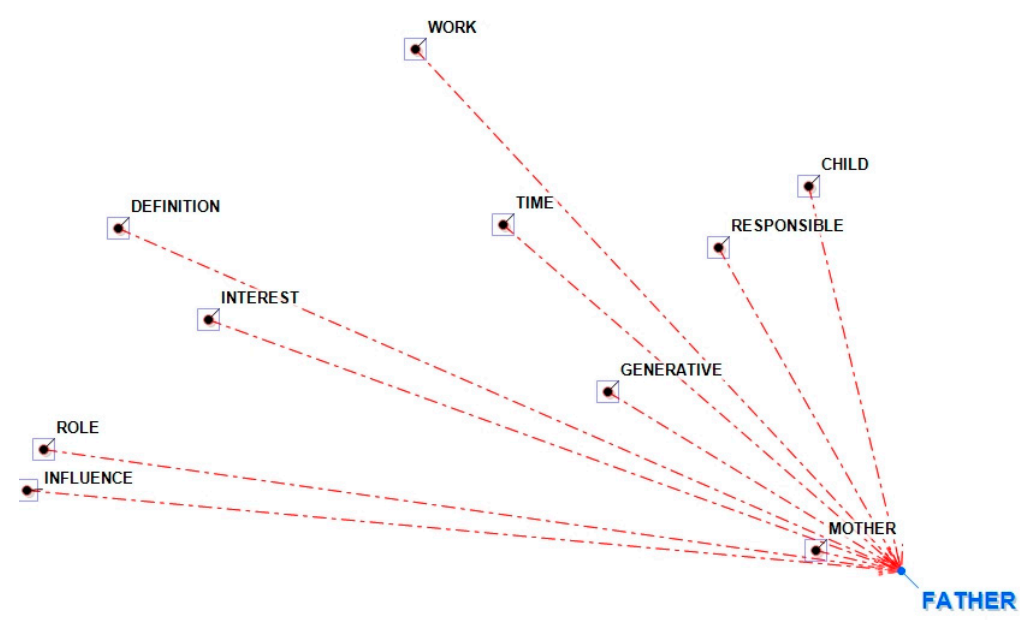

Figure 6. Predecessors of "father".

Stronger successors are "involvement" and, again, "mother"; weaker successors are "involve", "presence", "behaviour", "work", "role", "child" and "spend". The word "absence" appears at a distance (Figure 7).

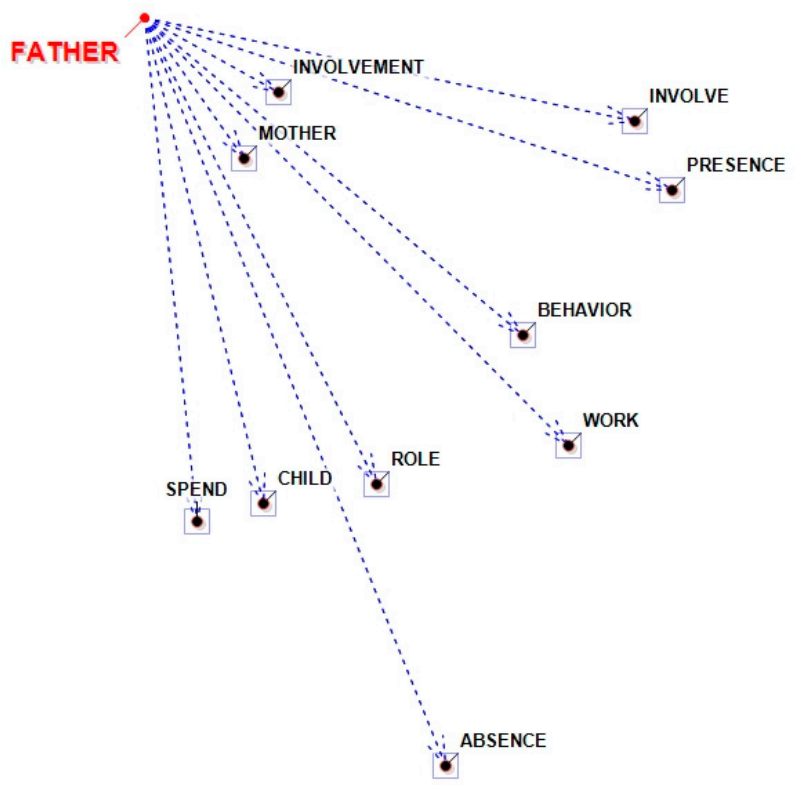

Figure 7. Successors of "father".

Looking at the terms that appear both as predecessors and as successors of the lexical unit "father" is interesting to highlight how fatherhood defines itself as a relationship with two fundamental figures, the mother and the child; the reference to the paternal role and the definition of paternity in reference to the working field ("work") also clearly emerges.

In comparing the predecessors and successors of the lemma "mother", some recursions appear compared to what has already been reported with the lemma "father": the attention to the child and to the topic of time as well as the focus on the relational ("relationship") and parental dimension ("parent") as well as the attention paid to the adolescent phase.

Instead, the accent on the role and its definition as well as on the work disappears; it is interesting to underline a change: while for the fathers "absence" is thematised, for the mothers "waiting" is thematised. 
According to graph theory. the predecessors and successors of each node (in our case, lexical units or themes) can be represented with arrows (arcs) in input (in-degree $=$ types of predecessors) or outgoing (out-degree $=$ types of successors). See Figure 8.

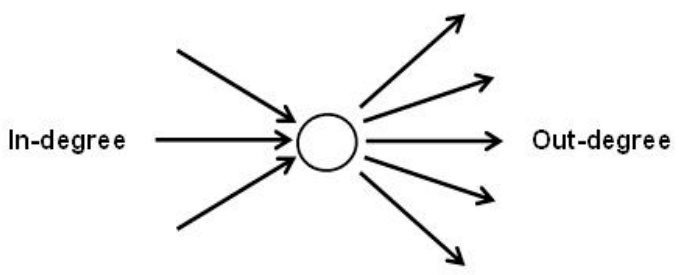

Figure 8. Predecessors and successors sccording to graph theory.

Based on their relationship (successors/predecessors), it is possible to verify the semantic variety generated by each node:

- $\quad$ if it is greater than it receives (ratio > 1), the node is called "source";

- $\quad$ if it is as large as it is received (ratio $=1$ ), the node is called "relay";

- $\quad$ if it is less than it receives (ratio $<1$ ), the node is defined as "absorbent".

In our case, "father" has 10 types of successors (out-degree) and 10 types of predecessors (in-degree), so it can be classified as a "relay" node.

\subsection{Paternity in the New Millennium}

\subsubsection{Radial Diagrams}

The lemma "father" (Figure 9)— the leading keyword in word associations—is associated with different subjects in relation to which the paternal function (child, in particular son and mother) is also defined here as a role that is played in the family, as already noted in the analysis of the literature from 1980-1999.

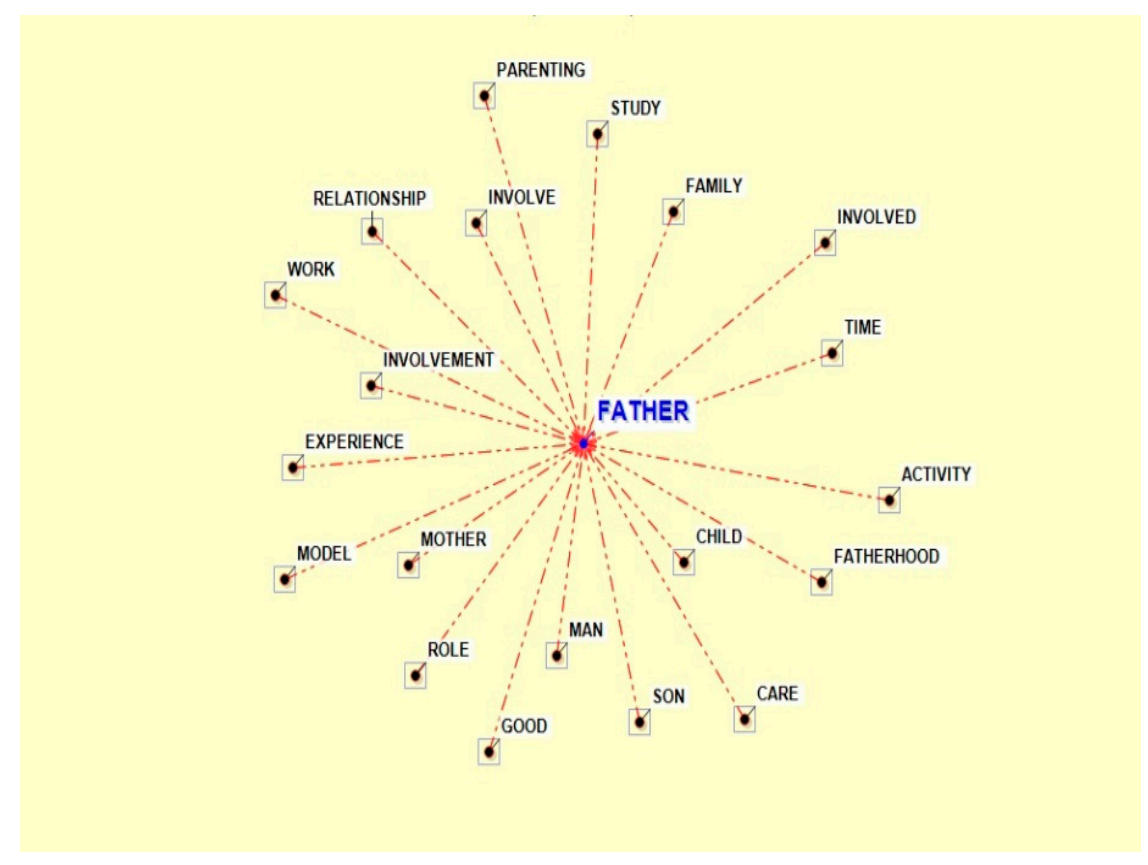

Figure 9. Radial diagram with "father".

A further element of commonality with the literature is that to define fatherhood, the references to masculinity (man) and to work are central; unlike this, however, there is a strong and explicit 
reference to the issue of care. Paternity is seen in a relationship in which great emphasis is given to the experiential aspect ("experience"), which is expressed in activities and practical parenting practices where dedicated time and involvement ("involved", "involve") are fundamental; this last aspect is the primary object of study and it is central in defining a model of a good father.

The focus placed on the relational and experiential dimension-where a leading role is reserved for the involvement-and on the modelling underlying the definition of fatherhood (good father model) represents a novelty in contemporary literature.

The lemma "child" (Figure 10)—in second place as a keyword in word associations—is associated with "mother", "father", "parent", "family" and concrete actions in which the dimension of parental care is explicit (i.e., "spend time", "involvement", "involve", "share", "play", "connect", defined as experience, activity and connection. As already noted for 1970-1999, the relational dimension ("relationship") and attention to the needs of the child are central; differently from it, however, the dimension of values and support is not themed but there is rather an emphasis on the ludic experiential and temporal dimension (paternity is displayed both on weekends and on weekdays).

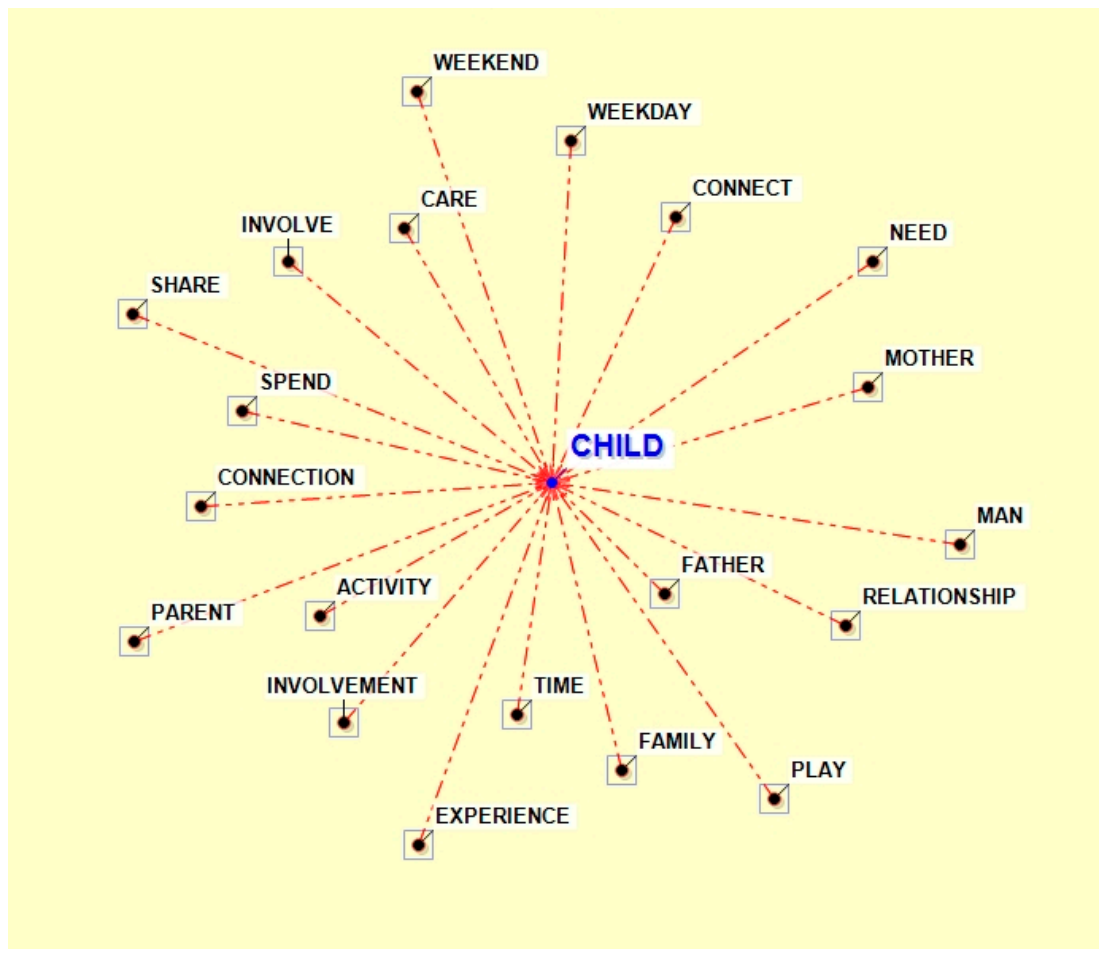

Figure 10. Radial diagram with "child".

The lemma "man" (Figure 11) —in third place as a keyword in word associations—is associated with "father", "father-figure", "fatherhood", "family", "child" and "woman". This confirms what emerged in the list of keywords: in today's literature the focus is on the issue of masculinity ("man") placed in relation to that of the most widely understood paternity; paternal involvement assumes a decisive role ("involve", "involved") as well as that of care and of the relationship with the world of work. In addition to the experiential aspect ("experience"), the attitudes ("attitude") and the different modalities to cover the role ("model") are also discussed. Finally, it is interesting to note the focus on the theme of intergenerational transmission ("generation"). 


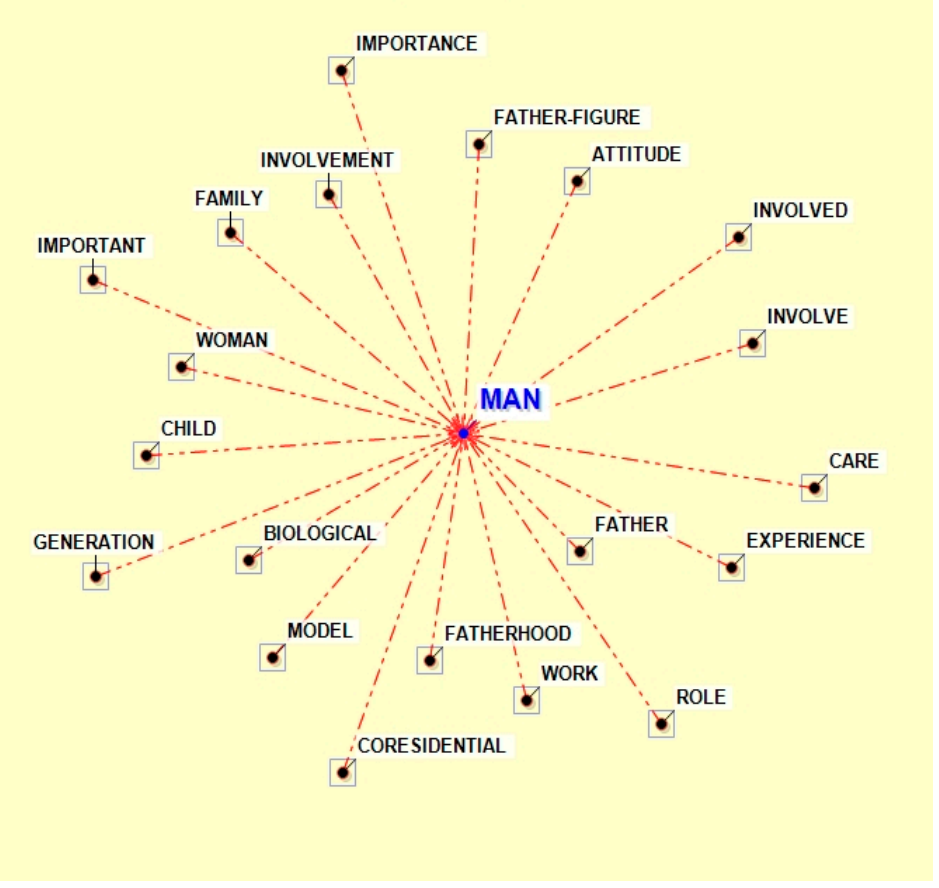

Figure 11. Radial diagram with Man.

Finally, the lemma "family" (Figure 12) - in fourth place as a keyword in word associations-is strongly associated with the themes of fatherhood ("father"), masculinity ("man") and parenting ("parent", "mother", "child"). The family is considered from a structural and relational ("relationship") point of view, focusing in particular on the intact family; membership ("member", "role", "involvement") is thematised, as is the dynamic-temporal aspect that refers to transition and change ("transition", "change", "time", "life"); the reference to the theme of generations is also interesting, as is the focus on the work environment, both as an activity and as remuneration ("income", "work").

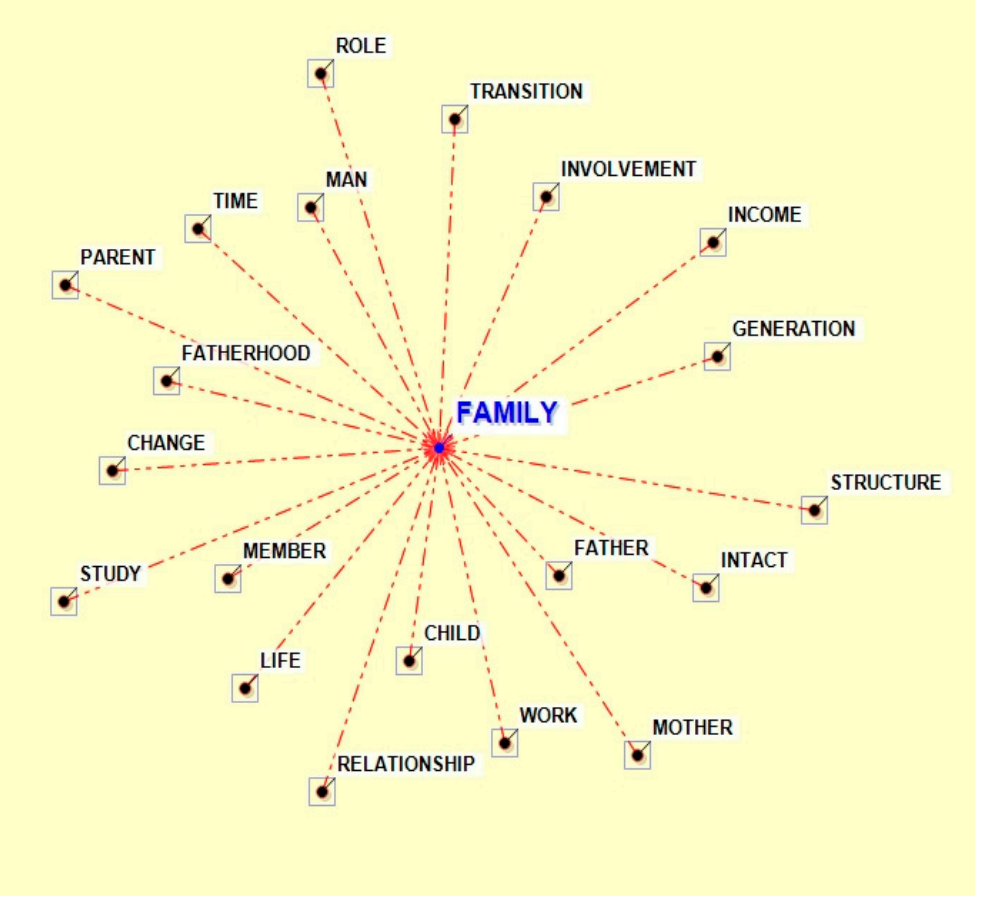

Figure 12. Radial diagram with "family". 


\subsubsection{Sequence Analysis}

Focusing on the analysis of keyword sequences, we identify here the predecessors and successors of the lexical unit "father".

Stronger predecessors are "biological", "good" and "mother"; intermediate predecessors are "time", "generative" and "man"; and weaker predecessors are "transition", "child", "experience" and "involved" (Figure 13).

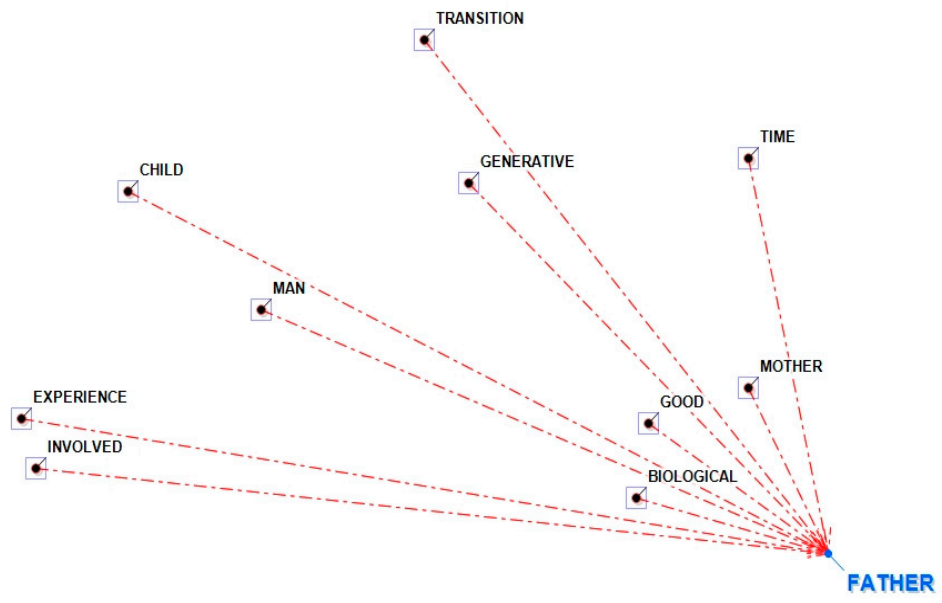

Figure 13. Predecessors of "father".

Comparing these results with what emerged from the years 1980-1999 literature, some recursive terms emerge - "mother", "child", "generative", "time" — and there are some changes: the reference to the workplace ("work") and the definition of role disappears, while the reference to what defines a good father and the link between fatherhood and masculinity ("man") are strong; although weaker, the focus on "transitions" is interesting.

The strongest successor is "involvement", followed closely in distance by "child" and "mother"; intermediate successors are "involve", "son", "role", "experience" and "describe". Weaker successors are "spend" and "family" (Figure 14).

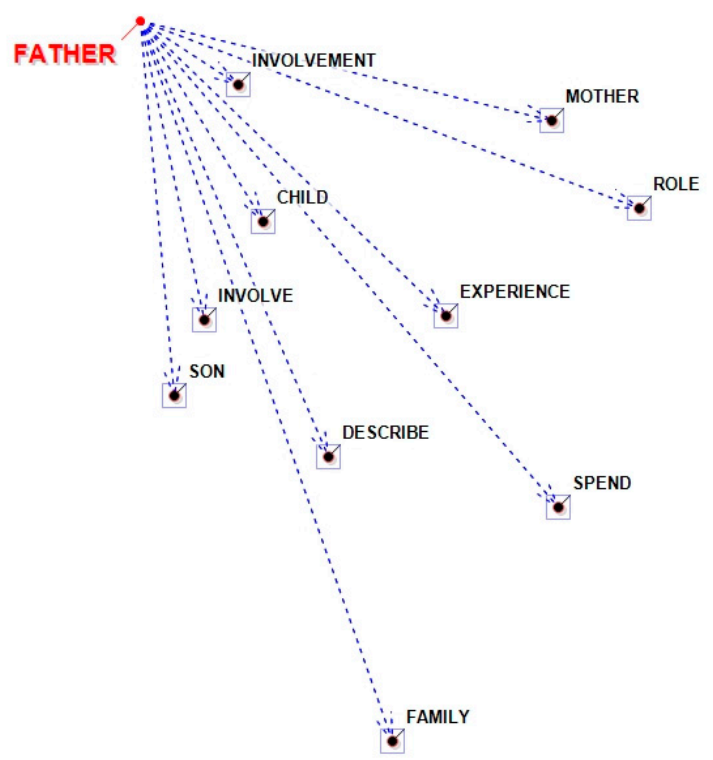

Figure 14. Successors of "father". 
Comparing these results with the analysis of the previous literature, here too some recursive terms emerge- "mother", "child", "involve", "involvement", "spend", "role"—and some innovations: the reference to the working field, the presence or absence of the paternal figure and behavioural dynamics ("behaviour") disappear while the reference to the experiential dimension ("experience") is strong.

Looking at the terms that appear both as predecessors and as successors of the lexical unit "father" in recent literature, it is interesting to highlight how fatherhood defines itself as a relationship with two fundamental figures, the mother and the child; the reference to the paternal involvement ("involved") and to the experience of paternity also clearly emerges.

According to graph theory (Section 3.2), finally, having father 10 types of successors (out-degree) and types of predecessors (in-degree) can be classified as a "relay" node.

\section{Conclusions}

The analysis carried out on a selection of literature in two different historical-social contexts was aimed at gathering possible differences from an international perspective with respect to the emergency representation of paternity. In particular, we asked two questions:

- Which aspects characterize the process of transformation of fatherhood, in an intergenerational perspective?

- How are paternal childcare practices represented in different historical and social periods?

Regarding the first question, the analysis of the keywords present in the two periods highlights first of all the centrality of the relational dimension (with the child, with the mother) already starting from the 1980s; this aspect is amplified starting from the new millennium with a broader meaning, including aspects related to masculinity, the cultural dimension of fatherhood and the different areas of life (family and work in the first place).

Paternity, in the years 1980-1999, is connected to concrete parental practices ("support", "suggest", "involve", "involvement", "spend time") and to both the generative and work dimensions. The theme of change is also central and above all the relational dimension ("relationship"): fatherhood is defined as a relationship with two fundamental figures, the mother and the child.

The theme of difference is also present: gender difference ("boy", "girl", "daughter") and age difference ("old", "young") of children ("child") and difference with the mother figure. The adolescent condition is analysed in relation to paternity and to the change in the parental role in the growth of children ("developmental"). The surveys with adolescent children focus on the theme of identity, on the relationship with the family (in particular with the mother figure) and on other specific topics ("discrepancy", "achievement", "expectation", "belief", "task").

The studies in the new millennium are placed in continuity with the previous ones, highlighting in addition to already known aspects some further themes: fatherhood is in fact associated with different subjects in relation to which one explicates one's role, within a dynamic relationship, especially with children and the mother. Here, however, there is an explicit reference to the theme of care, as well as of work: work and care are not considered as opposites but as dimensions equally present in the paternal experience.

Since the 2000s, paternity has taken on a broader and more complex sense, which includes masculinity ("man"). Great emphasis is also placed on the experiential aspect ("experience") of parenting; the focus is on dedicated time and involvement ("involve", "involved") in an attempt to identify paternity models and the characteristics of a good father.

Involvement is characterized as a key lemma in recent literature and is expressed as being present ("presence"), influencing ("influence") and requiring the devotion of time every day ("weekday") in awareness of diversity (different types or levels of involvement) and concrete activities.

To conclude, the analysis conducted, in line with previous theories (Dermott 2008; Doucet 2006; Miller 2011), seems to suggest a strong relationship between the two generations. Paternity in the 1980s 
and 1990s and in the new millennium is marked by great connections, rather than by discontinuity. Continuity is given by the relational dimension (with the mother and the child) as central aspects of paternal identity; recent studies include a specific reflection on masculinity in general. However we cannot conclude that new fathers as totally different from the previous generations, but different paternal style coexist. So, the paternal role is widened and deepened.

Moreover, keeping in mind the definition of generation given by the relational sociology (see the introduction) as the set of people who share a relationship both intra-family and in the social context, it is interesting to note that most of the literature on fatherhood has an intra-familiar focus (relationships with own father, the mother and children); it is rather difficult to see the social dimension of the intergenerational relationship of fatherhood/fathering. A more explicit tension toward a social dimension of fatherhood is given by considering the expression of masculinities in different social contexts as well as the importance of work in fathers life. From this perspective, fatherhood/fathering can be conceived as an intergenerational dimension articulated in different levels (personal, familiar and social) linked to one another.

With respect to the second research question, we also note a greater focus on the relationship with young children but less with adolescents; nevertheless, comparatively, we see a greater interest for the adolescent age in the years 1980-1999 compared to today. While in 1980-1999 some studies with a family perspective put the adolescent age in the spotlight, in the most recent years the reflection on the paternal involvement and on the different modalities with which this is expressed-favouring however the first years of life-prevails; studies on adolescence today do not look at it as a normative phase of the family (Marta et al. 2012; Scabini and Marta 2006) but focus mainly on non-normative transitions connected to it (e.g., adolescence in separate families).

Finally, regarding the relationship between the father and young adult children, we find in the literature that it is an important element for the well-being of the child and its importance emerges above all in the experience of divorce, associated with the removal of fathers from the domestic sphere, which contributes to impoverishment and deterioration of the father-young adult relationship (Greco 2006; Amato 1994).

Moreover, it should be emphasized that the relationship between fathers and young adult children is not particularly analysed, as is also evident from the analyses conducted. The studies that have taken it into consideration, mainly of a psychological nature, tend to analyse the negative aspects of intergenerational relations in terms of psychological distress or poor well-being (Umberson 1992; Lawton et al. 1994).

Sociological studies on the father and the young adult are practically absent. This is because the paternal role is structured in fact from early childhood and in relation to the mother. In this context, the intergenerational relationship immediately appears to be a very strong driver.

Although many studies, even in recent times, have highlighted the importance of maintaining a good parenting relationship after a divorce with a renewed interest in the father-child relationship, especially with young children, the adult father-child relationship is still left in the background.

Author Contributions: M.L.B. wrote Sections 1 and 2, S.M. Sections 3 and 4.

Conflicts of Interest: The authors declare no conflict of interest.

\section{References}

Amato, Paul R. 1994. Father-child relations, mother-child relations and offspring psychological well-being in early adulthood. Journal of Marriage and Family 56: 1031-42. [CrossRef]

Bosoni, Maria Letizia. 2014a. Breadwinners or involved fathers? Men, fathers and work in Italy. Journal of Comparative Family Studies XLV: 293-315.

Bosoni, Maria Letizia. 2014b. Men, fathers and work: The challenge of reconciliation. Case studies in some Italian companies. In Families, Care and Work-Life Balance Services: Case Studies of Best Practices. Edited by Elisabetta Carrà. Milano: Vita e Pensiero, Quaderni del Centro Famiglia, vol. 28, pp. 11-30. 
Bosoni, Maria Letizia, and Sarah Baker. 2015. The intergenerational transmission of fatherhood: A comparative study of the UK and Italy. Families, Relationships and Societies 4: 239-51. [CrossRef]

Bosoni, Maria Letizia, Isabella Crespi, and Elisabetta Ruspini. 2016. Between change and continuity: Fathers and work-family balance in Italy. In Balancing Work and Family in a Changing Society. The Fathers' Perspective. Edited by Isabella Crespi and Elisabetta Ruspini. Basingstoke: Palgrave Macmillan, pp. 129-45.

Brannen, Julia, and Ann Nilsen. 2006. From fatherhood to fathering: Transmission and change among British fathers in four-generation families. Sociology 40: 335-52. [CrossRef]

Brotherson, Sean E., David C. Dollahite, and Alan J. Hawkins. 2005. Generative fathering and the dynamics of connection between fathers and their children. Fathering 3: 1-28. [CrossRef]

Cipriani, Roberto. 2012. La religione dei valori. In I Valori Hanno Ancora Bisogno Della Religione? Edited by Sandro Belardinelli and Lorenza Gattamorta. Soveria Mannelli: Rubbettino, pp. 87-106.

Coleman, Lawrence, and Marilyn H. Ganong. 2003. Handbook of Contemporary Families: Considering the Past, Contemplating the Future. London: Sage Publications.

Craig, Lyn, and Killian Mullan. 2010. Parenthood. Gender and work-family time in the United States, Australia, Italy, France and Denmark. Journal of Marriage and Family 72: 1344-61. [CrossRef]

Crespi, Isabella, and Elisabetta Ruspini, eds. 2016. Balancing Work and Family in a Changing Society. The Fathers' Perspective. London: Palgrave Macmillan.

Dermott, Esther. 2008. Intimate Fatherhood. London: Routledge.

Donati, Pierpaolo. 2011. Relational Sociology. A New Paradigm for the Social Sciences. London and New York: Routledge.

Donati, Pierpaolo, and Ivo Colozzi, eds. 1997. Giovani e Generazioni. Quando si Cresce in una Società Eticamente Neutra. Bologna: Il Mulino.

Doucet, Andrea. 2006. Do Men Mother? Fathering. Care and Domestic Responsibility. Toronto: University of Toronto Press.

Featherstone, Brid. 2009. Contemporary Fathering: Theory, Policy and Practice. Bristol: Policy Press.

Finn, Mark, and Karen Henwood. 2009. Exploring masculinities within men's identificatory imaginings of first time fatherhood. British Journal of Social Psychology 48: 547-62. [CrossRef]

Gillies, Val. 2009. Understandings and experience of involved fathering in the United Kingdom: Exploring classed dimensions. The Annals of the American Academy of Political and Social Science 624: 49-60. [CrossRef]

Greco, Ondina. 2006. Il Lavoro Clinico con le Famiglie Complesse. Il Test La Doppia Luna Nella Ricerca e Nella Terapia. Milano: FrancoAngeli.

Gregory, Abigail, and Susan Milner. 2011. What is "new" about fatherhood? The social construction of fatherhood in France and the UK. Men and Masculinities 6: 1-19.

Halman, Loek. 1995. The Need for Theory in Comparative Research on Values. Tilburg: Tilburg University, Work and Organization Research Centre.

Hechter, Michael. 1993. Values research in the social and behavioral sciences. In The Origin of Values. Edited by Michael Hechter, Lynn Nadel and Richard E. Michod. New York: De Gruyter, pp. 1-28.

Hobson, Barbara. 2002. Making Men into Fathers: Men, Masculinities and the Social Politics of Fatherhood. Cambridge: Cambridge University Press.

Lamb, Michael E. 1999. The history of research on father involvement: An overview. Marriage E Family Review 29: 2-3.

LaRossa, Ralph. 2007. The culture and conduct of fatherhood in America, 1800 to 1960. Japanese Journal of Family Sociology 19: 87-98. [CrossRef]

LaRossa, Ralph, and Donald C. Reitzes. 1993. Symbolic interactionism and family studies. In Sourcebook of Family Theories and Methods. Edited by Pualine Boss, William Joseph Doherty, Ralph LaRossa, Walter Schumm and Suzanne Steinmetz. New York: Plenum, pp. 135-66.

LaRossa, Ralph, Charles Jaret, Malati Gadgil, and G. Robert Wynn. 2000. The changing culture of fatherhood in comic-strip families: A six-decade analysis. Journal of Marriage and the Family 62: 375-87. [CrossRef]

Lawton, Leora, Merril Silverstein, and Vern Bengtson. 1994. Affection, social contact and geographic distance between adult children and their parents. Journal of Marriage and Family 56: 57-68. [CrossRef]

Magaraggia, Sveva. 2013. Tensions between fatherhood and the social construction of masculinity in Italy. Current Sociology 61: 76-92. [CrossRef]

Marsiglio, William, Randal D. Day, and Michael E. Lamb. 2000. Exploring fatherhood diversity. Marriage E Family Review 29: 269-93. 
Marta, Elena, Margherita Lanz, and Semira Tagliabue. 2012. The transition to adulthood and generativity: A family generative climate. In Studi Interdisciplinari Sulla Famiglia. Milan: Vita e Pensiero, pp. 147-59.

Mazzucchelli, Sara. 2011. Reconciling Family-Work: The Role of Corporate Citizenship. Saarbrucken: LAP LAMBERT Academic Publishing GmbH \& Co.

McKinney, Cliff, and Kimberly Renk. 2008. Differential parenting between mothers and fathers: Implications for late adolescents. Journal of Family Issues 29: 806-27. [CrossRef]

Miller, Tina. 2011. Making Sense of Fatherhood: Gender, Caring and Work. Cambridge: Cambridge University Press.

Miller, Tina, and Esther Dermott. 2015. Contemporary fatherhood: Continuity, change and future. Families, Relationships and Societies 4: 179-81. [CrossRef]

Morman, Mark T., and Floyd Kory. 2006. Good fathering: Father and son perceptions of what it means to be a good father. Fathering 4: 113-36. [CrossRef]

Naldini, Manuela, and Paola Maria Torrioni. 2015. Modelli di maternità e di paternità in transizione. In $L a$ Transizione alla Genitorialità: Da Coppie Moderne a Famiglie Tradizionali. Edited by Naldini Manuela. Bologna: Il Mulino, pp. 205-26.

O'Brien, Margaret. 2009. Fathers, parental leave policies and infant quality of life. The Annals of the American Academy of Political and Social Science 624: 190-213. [CrossRef]

O’Brien, Margaret, and Karin Wall, eds. 2015. Comparative Perspectives on Work-Life Balance and Gender Equality: Fathers on Leave Alone. Dordrecht: Springer.

Palkovitz, Rob, and Glen Palm. 2009. Transitions within fathering. Fathering 7: 3-22. [CrossRef]

Perra, Margherita Sabrina, and Elisabetta Ruspini, eds. 2013. Men who work in "non-traditional" occupations. International Review of Sociology 23: 265-70. [CrossRef]

Rossi, Giovanna, and Sara Mazzucchelli. 2011. Paternità e maternità: Quale relazione? Sociologia e Politiche Sociali 14: 3 .

Rossi, Giovanna, Carrà Elisabetta, and Sara Mazzucchelli. 2009. Quali risorse per la transizione alla genitorialità? In Il Costo dei Figli. Quale Welfare per le Famiglie? Rapporto Cisf 2009 sulla Famiglia in Italia. Edited by Donati Pierpaolo. Milano: FrancoAngeli, pp. 208-50.

Ruspini, Elisabetta, and Maria Letizia Tanturri. 2017. Italy. In Father Involvement in the Early Years: An International Comparison of Policy and Practice. Edited by Marina A. Adler. Bristol: Policy Press, pp. 97-126.

Scabini, Eugenia, and Elena Marta. 2006. Changing intergenerational relationships. European Review 14: 81-98. [CrossRef]

Tanturri, Maria Letizia, and Letizia Mencarini. 2009. Fathers' Involvement in Daily Childcare Activities in Italy: Does a Work-Family Reconciliation Issue Exist? ChilD. Working Paper n. 22/2009. Available online: https:/ / annazavaritt.blog.ilsole24ore.com/wp-content/uploads/sites/54/files/fathersinvolvement-in-daily-childcare-activities.pdf (accessed on 8 April 2019).

Terenzi, Paolo, Lucia Boccacin, and Riccardo Prandini. 2016. Lessico Della Sociologia Relazionale. Bologna: Il Mulino.

Umberson, Debra. 1992. Relationships between adult children and their parents: Psychological consequences for both generations. Journal of Marriage and Family 54: 664-74. [CrossRef]

Yeung, W. Jean, John F. Sandberg, Pamela Davis-Kean, and Sandra L. Hofferth. 2001. Children's time with fathers in intact families. Journal of Marriage and Family 63: 136-54. [CrossRef]

Zajczyk, Francesca, and Elisabetta Ruspini. 2008. Nuovi padri? Mutamenti Della Paternità in Italia e in Europa. Milano: Baldini Castoldi Dalai Editore.

(C) 2019 by the authors. Licensee MDPI, Basel, Switzerland. This article is an open access article distributed under the terms and conditions of the Creative Commons Attribution (CC BY) license (http:/ / creativecommons.org/licenses/by/4.0/). 